\title{
Toxicity of co-trimoxazole in nutritional haematinic deficiency
}

\author{
A. V. L. HILL \\ M.R.C.P.
}

\author{
D. N. S. KERR \\ M.Sc., F.R.C.P.
}

Department of Medicine, Royal Victoria Infirmary, Newcastle-upon-Tyne NE1 4LP

\begin{abstract}
Summary
A woman of 47 habituated to analgesics and living on an inadequate diet was deficient in iron, folate and vitamin $\mathbf{B}_{12}$. Treatment of pyelonephritis with cotrimoxazole precipitated pancytopenia with a megaloblastic bone marrow. She recovered following withdrawal of the drug and administration of iron, folate and vitamin $B_{12}$.
\end{abstract}

\section{Introduction}

Co-trimoxazole is an antibacterial combination of trimethoprim and sulphamethoxazole which acts by sequentially blockading folate metabolism (Elion, Singer \& Hitchings, 1954; Darrell, Garrod \& Waterworth, 1968). Cases of haematological toxicity have been reported following its use in patients with initially normal haematological status (Kahn, Fein \& Brodsky, 1968; Paulley, 1970; McPherson \& Raik, 1970; Geddes et al., 1971; Jewkes, Edwards \& Grant, 1970; Jenkins, Hughes \& Hall, 1970; Hulme \& Reeves, 1971) but only a few have been of such severity as to be clinically significant.

Chanarin \& England (1972) reported the use of co-trimoxazole in four patients with known megaloblastic anaemia due to vitamin $\mathbf{B}_{12}$ or folate deficiency. There was suppression of the reticulocyte response in all, pancytopenia in two and anaemia with neutropenia in a third. We report serious pancytopenia following the administration of cotrimoxazole to a patient with iron, folate and vitamin $\mathbf{B}_{\mathbf{1 2}}$ deficiency.

\section{Case report}

Mrs M.M., a 47-year-old restaurant manageress, was admitted with acute renal failure precipitated by pyelonephritis with a coliform organism. She had taken 100 Compound Codeine tablets BPC per week for many years, with a recent increase in dose. Due to overwork and the constant smell of cooking she had a poor appetite for at least 5 years and her standard meal was jam and bread. She was pale, dehydrated, semiconscious and had Kussmaul breathing and bilateral loin tenderness. Her plasma urea was $240 \mathrm{mg} / 100 \mathrm{ml}$, sodium 114 , potassium $5 \cdot 4$, chloride 74 , and bicarbonate $9 \mathrm{mEq} / \mathrm{l}$, haemoglobin $9.1 \mathrm{~g} / 100 \mathrm{ml}$, MCHC $29 \%$, WCC 8600 ,

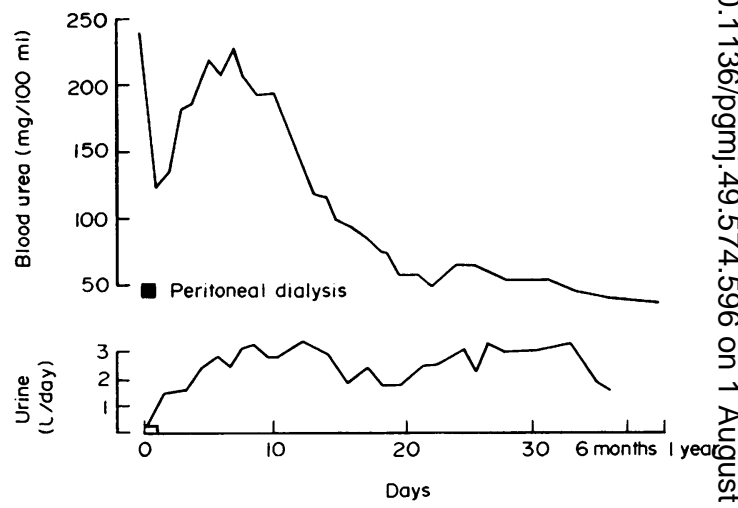

FIG. 1. Response of blood urea and urine output tô $\vec{\emptyset}$ treatment.

platelets $220,000 / \mathrm{mm}^{3}$, serum iron 80 , iron binding capacity $302 \mathrm{mg} / 100 \mathrm{ml}$. Serum folate and vitamin̄̄ $B_{12}$ levels were requested but were not reported untilő 10 days later.

She was treated by rehydration, peritoneal dialysis $\overrightarrow{\vec{A}}$ and co-trimoxazole two tablets twice a day for $14 \stackrel{3}{3}$ days. Her renal function rapidly improved (Fig. 1). Eighteen months later her serum creatinine is $0.8 \mathrm{mg} / \overrightarrow{0}$ $100 \mathrm{ml}$ and her creatinine clearance has risen to $70 \mathrm{ml} / \mathrm{min}$. Her haematological changes are shown 3 . in Fig. 2. The haemoglobin dropped to $7.4 \mathrm{~g} / 100 \mathrm{ml}$ 음 after rehydration and fell further to $5.7 \mathrm{~g} / 100 \mathrm{ml}$ on the 10th day, by which time she had a leukopenia of $1400 / \mathrm{mm}^{3}$ and a thrombocytopenia of $60,000 / \mathrm{mm}^{3}$. Bone marrow aspirate showed megaloblastic 의 haematopoiesis, and at this time it was ascertained $D$ that her initial folate level was $1.4 \mathrm{ng} / \mathrm{ml}$ and her음 vitamin $B_{12}$ was less than $100 \mathrm{pg} / \mathrm{ml}$.

Her drug therapy was reviewed. She had received $\stackrel{\text { S }}{\text { s. }}$ sulphamethizole and nalidixic acid for 1 week prior $N$ to admission and oral sodium bicarbonate, sodium $\mathrm{N}^{\mathrm{\omega}}$ chloride, slow release potassium chloride, ferrous gluconate, co-trimoxazole and intravenous saline inco in the ward. Of these, co-trimoxazole seemed much $\mathbb{\mathbb { D }}$ the most likely precipitant of her pancytopenia at $\stackrel{\mathcal{S}}{+}$ a time when her renal function was improving. She 0 was given $5 \mathrm{mg}$ folic acid orally three times a day and vitamin $B_{12} 100 \mu \mathrm{g}$ intramuscularly, daily at first 


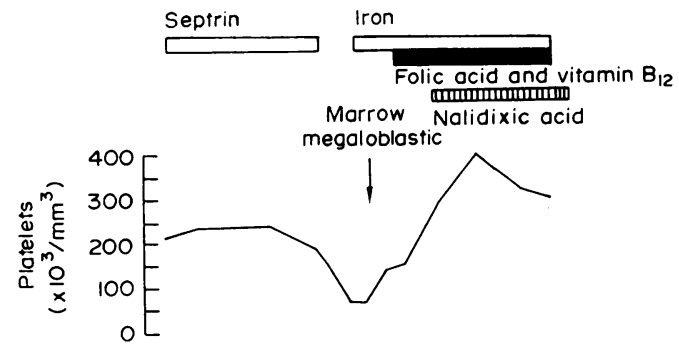

teristic of the disease at an early stage (Bell et al., 1969; Murray, Lawson \& Linton, 1971). However, it implies that she could not have had severe renal impairment before her pyelonephritis and her initial anaemia was therefore out of proportion to her renal dysfunction (Pennington \& Kincaid-Smith, 1971). This anaemia was partly due to iron deficiency, presumably resulting from gastric bleeding induced by the analgesic, menstruation and her poor diet. The folate and vitamin $\mathbf{B}_{12}$ deficiency were attributed to dietary inadequacy as barium meal and follow-through examination, faecal fat excretion, xylose excretion, and absorption studies of vitamin $B_{12}$ and folate were all normal.

We do not know for certain that her haematopoiesis was normoblastic on admission, but her blood film showed no evidence of macrocytic anaemia and her white cell and platelet counts were not depressed. The precipitation of life-threatening pancytopenia was probably the result of co-trimoxazole administration to a patient with subclinical deficiency of folate and vitamin $\mathbf{B}_{12}$. Since this complication with megaloblastic anaemia is not produced by sulphonamides alone trimethoprim is the presumptive cause (Chanarin \& England, 1972).

Co-trimoxazole is a very effective antibacterial

FIg. 2. Peripheral blood changes during co-trimoxazole therapy and treatment with oral iron and folic acid and intramuscular vitamin $\mathbf{B}_{12}$.

then at wider intervals; co-trimoxazole was withdrawn on the 14th day. There was a peak reticulocyte response of only $6 \%$, possibly due to a septicaemia which was detected 1 week later, and on discharge after 3 weeks of haematinic therapy her haemoglobin was $7 \cdot 7 \mathrm{~g} / 100 \mathrm{ml}$, WCC 9400 and platelets $300,000 / \mathrm{mm}^{3}$. Folate and vitamin $B_{12}$ were discontinued after 2 months and with improved diet she has maintained normal blood counts apart from a slight anaemia for 18 months.

During the period of leukopenia she developed a low grade fever and coliforms were grown from her blood stream on two occasions, and from her urine on one occasion. She responded to a 6-week course of nalidixic acid. Her urine has remained sterile, though she has the persistent pyuria typical of analgesic nephropathy (Dawborn et al., 1966; Bell et al., 1969).

\section{Discussion}

We presume that Mrs M.M. was suffering from early analgesic nephropathy complicated by acute pyelonephritis, which is a common and sometimes lethal complication of this disease (Bell et al., 1969). Her IVP after recovery was normal, but this by no means excludes analgesic nephropathy (Fairley \& Kincaid-Smith, 1968). The recovery of good renal function after withdrawal of analgesics is characincreasingly popular in the treatment of many infections, notably those of the urinary tract (Dargie et al., 1971; Gavras, Lawson \& Linton, 1971, Cattell et al., 1971). In view of this experience, and those of Chanarin \& Edwards, patients who are at risk of folate deficiency-pregnant women on poor diets, those taking anticonvulsants, the debilitated elderly, etc. - should be assessed for folate and $B_{12}$ deficiency before treatment with long courses of co-trimoxazole. Particular care should be taken with patients on immunosuppressive drugs (Hulme \& Reeves, 1971).

\section{Addendum}

Since this manuscript was accepted Yuill (1973) has described megaloblastic anaemia following administration of co-trimoxazole to a patient probably depleted of folic acid by dietary restriction and peritoneal dialysis.

\section{References}

Bell, D., KerR, D.N.S., Swinney, J. \& Yeates, W.K. (1969) Analgesic nephropathy. Clinical course after withdrawal of phenacetin. British Medical Journal, 3, 378.

Cattell, W.R., Chamberlain, D.A., Fry, I.K., McSherry, M.A., Broughton, C. \& O'Grady, F. (1971) Long term control of bacteriuria with trimethoprim-sulphonamide. British Medical Journal, 1, 377.

Chanarin, I. \& England, J.M. (1972) Toxicity of 1rimethoprim-sulphamethoxazole in patients with megaloblastic haemopoiesis. British Medical Journal, 1, 651. 
Dargie, H.J., Allison, M.E.M., McGeachie, J., MaCDonAld, G.A. \& KENNEDY, A.C. (1971) Long-term trimethoprim-sulphamethoxazole in the management of recurrent urinary infection. Scottish Medical Journal, 16, 504.

Darrell, J.H., Garkod, L.P. \& WaterWorth, P.M. (1968) Trimethoprim: laboratory and clinical studies. Journal of Clinical Pathology, 21, 202.

Dawborn, J.K., Fairley, K.F., Kincald-Smith, P. \& KING, W.E. (1966) The association of peptic ulceration, chronic renal disease, and analgesic abuse. Quarterly Journal of Medicine, 35, 69,

Elion, G.B., Singer, G. \& Hitchings, G.H. (1954) Antagonists of nucleic acid derivatives. VIII. Synergism in combinations of biochemically related antimetabolites. Journal of Biological Chemistry, 208, 477.

FAIRLEY, K.F. \& KINCAID-SmITH, P. (1968) Renal papillary necrosis with a normal pyelogram. British Medical Journal, $1,156$.

Gavras, H., Lawson, D.H. \& Linton, A.L. (1971) Extended therapy with a trimethoprim-sulphonamide for the treatment of established urinary tract infection. Scottish Medical Journal, 16, 506.

GedDES, A.M., Fothergill, R., GoOdall, J.A.D. \& DORKEN, P.R. (1971) Evaluation of trimethoprim-sulphamethoxazole compound in treatment of Salmonella infections. British Medical Journal, 3, 451.
Hulme, B. \& Reeves, D.S. (1971) Leucopenia associated with trimethoprim-sulphamethoxazole after renal transplantation. British Medical Journal, 3, 610.

Jenkins, G.C., Hughes, D.T.D. \& Hall, P.C. (1970) A $\subseteq$ haematological study of patients receiving long-term treatment with trimethoprim and sulphonamide. Journal $\stackrel{5}{\rightarrow}$ of Clinical Pathology, 23, 392.

JewKes, R.F., EDWARDS, M.S. \& Grant, B.J.B. (1970) Haematological changes in a patient on long-term treat- $\bar{\omega}$ ment with a trimethoprim-sulphonamide combination. 7 Postgraduate Medical Journal, 46, 723.

KAHN, S.B., FeIN, S.A. \& BrodsKy, I. (1968) Effects of trimethoprim on folate metabolism in man. Clinical Pharmacology and Therapeutics, 9, 550.

MCPherson, V.J. \& RAIK, E. (1970) Thrombocytopenia following administration of Septrin. Medical Journal of $\vec{\omega}$ Australia, 2, 754.

MurRay, R.M., Lawson, D.H. \& Linton, A.L. (1971) ृृ Analgesic nephropathy: clinical syndrome and prognosis. British Medical Journal, 1, 479.

Paulley, J.W. (1970) Drug neutropenia. British Medical है Journal, 2, 364

Penington, D.G. \& Kincaid-Smith, P. (1971) Anaemia in renal failure. British Medical Bulletin, 27, 136, 141.

YuILL, G.M. (1973) Megaloblastic anaemia due to trimethoprim-sulphamethoxazole therapy in uraemia. Postgraduate Medical Journal, 49, 100.

\title{
Pseudo-pseudo-hypoparathyroidism with coarctation of the aorta- a clinical syndrome?
}

\author{
J. DE SWIET \\ M.D., F.R.C.P. \\ Department of General Medicine, East Glamorgan General Hospital, Pontypridd, Glamorgan
}

\begin{abstract}
Summary
Two cases of pseudo-pseudo-hypoparathyroidism are described, associated with coarctation of the aorta, suggesting a further common clinical link (besides those already recognized) between the former condition and Turner's syndrome. The need for a change of nomenclature of pseudo-pseudo-hypoparathyroidism is emphasized.
\end{abstract}

\section{Case no. 1.}

A single woman, aged 50, was referred for opinion because of recent dyspnoea. She had not been allowed to play games at school because of 'some heart condition', but had led a normal life in all other respects, and had always menstruated normally. Her father had died of 'a heart complaint', her mother was alive but was being treated for pernicious anaemia, and her sister had 'rheumatism'.

On examination she was short (height $145 \mathrm{~cm}$ ) and weighed $62 \mathrm{~kg}$. She had a rounded facies, small hands and feet, and a recessed knuckle of the left fifth finger. BP $240 / 100 \mathrm{mmHg}$ in the right arm. No femoral or other leg pulses could be felt, but there was a prominent carotid pulse bilaterally and collateral arterial pulsations were felt over the thorax. No thrills were felt, but there was a loud, highpitched ejection-type systolic murmur all over the front of the chest. A chest X-ray showed gross notching of several ribs, an elongated aortic knuckle, and post-stenotic dilatation of the descending aorta. $\mathrm{X}$-ray of the hands confirmed their small appearance and the shortening of the left fifth metacarpal. An ECG showed left ventricular hypertrophy with neg- o ative $T$ waves in leads $1, V L$ and V6. The patient $N$ refused admission to hospital for further investiga- N tion to confirm the clinical diagnosis of coarctation, and to exclude associated cardiac lesions; but it was felt that the diagnosis was reasonably certain in view of the physical signs and radiological features. The following investigations were normal: blood urea and electrolytes, routine urinalysis, serum calcium, phosphorus and alkaline phosphatase, haematological 